\title{
Differentiating Instruction in the Language Learning Classroom: Theoretical Considerations and Practical Applications
}

\author{
Diego P. Ortega \\ Universidad Nacional de Educación (UNAE), Azogues, Ecuador \\ Johanna M. Cabrera \\ Universidad Nacional de Educación (UNAE), Azogues, Ecuador \\ Jhonny V. Benalcázar \\ Escuela de Educación Básica Héctor Sempértegui García, Cuenca, Ecuador
}

\begin{abstract}
Differentiated instruction (DI) is a topic that has attracted the attention of in-service and pre-service teachers, teacher educators and educational authorities in the last few decades, because of its great importance and several different affordances for better student learning. In this sense, this article attempts to provide content-area, classroom teachers and English language teachers with a solid understanding of what DI entails by learning about its key characteristics and fundamental reasons for the use of DI within the classroom context. Moreover, the importance behind modifying content, process, and product is not only analyzed in this paper but also the value of adjusting the learning environment is examined as well. Then a brief narrative of a teaching situation in an EFL context is highlighted in order to set the stage and explain the necessity of the implementation of a DI model into the classroom, so that students can experience meaningful and successful language learning. Afterwards, practical applications, based on meaningful and varied ways to differentiate instruction are included, so that language teachers find it easier to help students achieve learning standards. It is concluded that DI helps teachers be responsive to leaners' needs, interests, ability and language proficiency levels, and learning styles, as DI puts students at the center of teaching and learning, promotes equity and academic excellence, and acknowledges student uniqueness
\end{abstract}

Index Terms — education, language instruction, standards, English, foreign languages

\section{INTRODUCTION}

Differentiated instruction (DI) is an instructional strategy intended to help educators succeed their diverse student population along the process of teaching and learning. Before DI is incorporated into the classroom, it is key for teachers to identify learners' readiness levels, interests, and learning profiles. By doing so, teachers will be able to employ DI effectively during the course of instruction, which consequently will enhance teaching, support and improve learning for all learners. It is important because in today's world there is a need to enhance teaching and student learning due to the many differences students bring with them to the teaching-learning process and the several factors that have a significant impact upon the ways students make sense of the intended input, approach the learning process, and demonstrate their gained knowledge and skills. Therefore, teaching needs to be responsive to these differences so that learners can receive appropriate support, guidance, and meaningful learning experiences in order for students to become successful and reach their potential at school.

With the aim of making informed teacher decisions and enhancing classroom instruction through the use of DI, this paper starts by providing a review of the literature on the topic at hand, which is concerned with defining differentiated instruction, characteristics of DI, a rationale for using DI in today's classroom, and adjusting content, process, and product in the differentiated classroom. This part of the paper is intended to provide a good understanding of the conceptualization and key components of DI as well as its importance in the field of education. Later a narrative of a teaching situation in our home country is provided, which highlights language learners' needs and interests and acknowledges a shift in classroom practice. Lastly, a critical learning opportunity where theory meets practice is discussed, where we reflect on the ways content, process, product, and the learning environment can be differentiated within the Ecuadorian teaching-learning context. In so doing, we engage ourselves in creative and critical thinking to create a differentiated classroom instruction and to help students accomplish established standards.

\section{UNDERSTANDING DIFFERENTIATED INSTRUCTION}


There are various definitions of differentiated instruction in the literature; across definitions some important things are given special emphasis, such as an acknowledgment of students' varied background knowledge, language, culture, readiness, preferences in learning, interests, needs and learning profiles. Differentiated instruction (DI) cannot be viewed as an instructional strategy but as an approach for teaching and learning. Such approach is intended to be used with students who are academically diverse within the same classroom setting. Differentiated instruction attempts to maximize each student's growth and individual success by making adjustments or modifications in the content, process, and product. This instruction model also intends to meet each student where he or she is on the learning continuum (Heacox, 2012; Rock et al., 2008; Tomlinson et al., 2003).

According to Pham (2012), differentiation is an approach that involves "identifying students' readiness levels, modifying instruction, applying collaboration and autonomy in learning, and integrating teaching and practice to enhance learning" (p.18). Pham (2012) went on explaining that such approach must include various teaching methods and activities, several assessment procedures, and an ongoing needs analysis in order to "maximize academic success based on student readiness" (p.18).

Tomlinson and colleagues (2003) presented a definition of differentiated instruction that encompassed consistently the various ideas on the kind of instruction discussed above. The definition, given by the scholars, focuses on making adaptations, addressing learners' needs, and maximizing learning for all students. In other words, DI is a teaching approach in which "teachers proactively modify curricula, teaching methods, resources, learning activities, and student products to address the diverse needs of individual students and small groups of students to maximize the learning opportunity for each student in a classroom" (Tomlinson et al., 2003, p.121).

\section{A. Key Characteristics of Differentiated Instruction}

Characteristics in common were identified in the reviewed literature. Knowing the characteristics of differentiated instruction is key in order to have a better understanding of how a classroom that uses this kind of instruction looks like. According to Tomlinson et al. (2003), differentiated instruction is characterized by providing students with classroom instruction that suits to their varied readiness levels, interests, learning necessities, and preferred modes of learning. In this way, learners can experience meaningful opportunities for effective learning and growth as well. Pham (2012) added that teachers need to know about cognitive development and readiness levels because they have a big impact on student learning and performance.

When differentiated instruction is employed, it is critical to make careful, informed decision making in order to support student learning and improve academic performance along the teaching-learning process. In this respect employing appropriate instructional techniques and strategies are key in the classroom setting (Pham, 2012). Subban (2006) pointed out that DI is responsive to student populations as these become culturally, socially, and academically diverse over time. In the increasing student diversity classroom, DI promotes meaning and engaging learning across learners in the same learning environment. As stated in Smit and Humpert (2012), characteristics of a differentiated classroom were incorporated into DI, and they read as follows: students' differences are closely paid attention, formative assessment has a central part for determining subsequent instruction, the teacher and students work collaboratively along the learning process, and teachers make suitable adjustments to the content, process, and according to learners' needs.

Kalbfleisch (1998) emphasized that differentiated classrooms are "responsive to students' varying readiness levels, varying interests, and varying learning profiles" (as cited in Lawrence-Brown, 2004, p.37). Additionally, LawrenceBrown (2004) stated a differentiated classroom needs an instructional planning that views the classroom as a community where individual learners are nourished. "All students benefit from the availability of a variety of methods and supports, and an appropriate balance of challenge and success" (Lawrence-Brown, 2004, p. 37). As a result, DI is significantly relevant for both students who find school easy as well as for those who struggle in the learning process. Put it more simply and from a differentiated instruction point of view, a classroom is a learning environment where all students - struggling and advanced students - benefit on a daily basis towards academic success.

\section{B. A Rationale for Using Differentiated Instruction in the Classroom}

After various definitions of DI and its characteristics were presented above, it is now important to know the reasons behind the incorporation of DI at the school setting. First and foremost, there are student populations that are culturally, socially, and academically diverse in today's classrooms. Thus, classrooms are typified by learners who underachieve and excel, students whose first language is other than the language of instruction, students from diverse cultures and socio economic backgrounds, students from different sexual orientations, motivated and unmotivated learners, and students of varied interests and modes of learning (Sapon-Shevin, 2000/2001). In addition to the existing need of using a classroom instruction aims to addressing the characteristics of today's student populations, schools' efforts towards helping students to overcome reading problems as well as actions towards enhancing literacy instruction in the regular classroom have been identified (Allington, 2003).

With the before-mentioned ideas in mind, it is imperative to take into account that schools require teachers to make adjustments on curriculum, materials, and assessment. In addition to this, teachers hold accountability in ensuring that all students have access to high-quality learning. Thus, differentiated instruction comes in handy to support and guide the task of teaching and schools' efforts to reach all learners within a challenging and diverse classroom context so that 
"students [can] receive instruction suited to their varied readiness levels, interests, and learning preferences, thus enabling them to maximize the opportunity for growth" (Tomlinson et al., 2003, p.120).

\section{Adjusting Content, Process, and Product in the Differentiated Classroom}

As stated by Pham (2012), differentiated instruction includes modifying the content, the process, and the product. Making modifications on these three areas can support and improve student learning because students "grasp key aspects of instruction in the most effective way, as well as evaluate student performance accurately" (Pham, 2012, p. 17). According to Bigge and Shermis (2004), the intended content should be challenging but controllable for the learners. On the contrary, students will fall behind and feel discouraged. This principle relates well to Vygotsky's Zone of Proximal Development. Therefore, it is important to modify the content by adjusting learners' developmental progress and their range of development. Additionally, Pham (2012) stated that "content modification should emphasize key dimensions of instruction for desired learning outcomes" (p.16). It is imperative to focus on the essentials of instruction; this is a principle that teachers should take into account for effective differentiation (Pham, 2012). Heacox (2012) agreed that by focusing on the most crucial concepts, processes, and skills teachers differentiate instruction. Heacox (2012) went on explaining that teachers differentiate content when pre-assessment is conducted, so that they can learn about their "students' skills and knowledge [in order to] match learners with appropriate activities according to readiness... [,] give students choices about topics to explore in greater depth... [, and] provide students with basic and advanced resources that match their current levels of understanding" (p. 10).

Pham (2012) pointed out that modifying the process involves employing distinct activities, tasks, teaching techniques and strategies aimed at helping students obtain the new learning. Ideally, teachers should plan instruction in a logical sequence so that students can move from easy to difficult and/or from concrete to abstract. Pham (2012) noted that "the main objective of modifying the instructional process is to make every single lesson meaningful and applicable to learners in an academically enriched context" (p.16). Heacox (2012) asserted that in a differentiated instruction model our students' learning profiles and preferences are reflected in the way teachers conduct their instruction. In this respect process can be modified "by adding greater complexity, or abstractedness to tasks, by engaging students in critical and creative thinking, or by increasing the variety of ways in which you ask them to learn" (Heacox, 2012, p. 11).

Lastly, modifying the product of instruction is concerned with allowing learners to demonstrate in various modes their attainment of the new learning. Pham (2012) commented using different forms of assignments is key because learners are more likely to demonstrate the things they have learned by putting the acquired learning into practice. Therefore, teachers should look for assessment procedures that reflect what things learners have been instructed, and such procedures should ideally be performed every day. After assessment is conducted, effective feedback must be provided to all students before further instruction is delivered. Heacox (2012) eloquently added, "Products reflect what students have understood and been able to apply. They show learning in use and may reveal new thinking or ideas" ( $p$. 11).

Smit and Humpert (2012) conducted a research project in rural and alpine small schools in the eastern part of Switzerland. The purpose of the project was to obtain an overview of DI within the above-mentioned research context. A total of 1180 students and 162 teachers responded to the questionnaires used in the study. Several participating teachers reported that they often employed strategies of DI in their classrooms. Through an in-depth analysis it was revealed that certain teachers had a better understanding of DI than others. Teachers applied DI strategies mostly once a week, while those who were involved in further responsibilities, including coaching and teaching staff, used these strategies every day. In general, the study teachers mainly practiced DI by making modifications on the content and process. For instance, teachers differentiated tasks and goals, adjusted the allotted time for tasks, varied the number of tasks, and individualized student learning. Another finding revealed that only a few teachers diagnosed their students' prior knowledge and employed formative assessment. The study concluded that the participating teachers do not yet employ a significant, effective practice of DI. An evident lack regarding making modifications on the product was more evident than adjusting the content and process.

In a study conducted by Logan (2011), 141 middle school teachers from southeast Georgia were administered a survey with the aim of determining their level of knowledge in applying differentiated instruction in the classroom setting. The survey included 16 questions that were concerned about the essential principles, the essential components and the common myths surrounding differentiated instruction. The participating teachers' responses demonstrated that there was an understanding of and an agreement on the key principles of DI. Regarding the essential components of DI teachers manifested that making modifications on processes, products, content, and materials is crucial in a differentiated instruction model. With regard to myths surrounding differentiated instruction, teachers do not agree on two important myths according to the researcher. First, teachers disagreed at over $90 \%$ on the myth that there is one single way to differentiate instruction. This finding aligns with the notion that there is no established rules for differentiated instruction rather this instruction approach "is about understanding the developmental level of students and differentiated practices" (Logan, 2011, p. 9). Second, teachers disagreed at over $85 \%$ on the myth that every student needs to demonstrate mastery of learning on the same day of grading. According to Logan (2012), this finding is quite important because it indicates that teachers may start beginning to modify their thinking about their task of grading. Logan (2012) added that "it does not matter when students demonstrate mastery if they sincerely work along the way" (p. 9). 
Reis and colleagues (2011) carried out an experimental study intended to examine the effect of a differentiated, enriched reading program on students reading fluency and comprehension. The authors noted that it was the first research project that explored the use of differentiated instruction in contrast with whole or small group reading instruction in five elementary schools. The sample included 63 teachers and 1,192 students in second to fifth grades. The study concluded that differentiated instruction and the employed teaching methods (i.e. high interest and selfselected books) were effective for a higher level of reading fluency and comprehension in some students. Scott's (2012) study results also indicated that differentiated instruction did not have an impact on the academic achievement in mathematics of all the participating subjects from three second grade classrooms. In the study, differentiated instruction had a significant impact on students with a higher academic ability.

\section{ConteXtuAlizing A TeAChing SituAtion BeFore The IMPLEMENTATION OF DI}

In Ecuador, there are people who come from three major ethnic backgrounds-mestizos (mixed Amerindian and Spanish), indigenous people from 12 distinct communities, and Afro- Ecuadorians. Jackson (2007) claimed, "The biggest groups of ethnic minorities in Ecuador are the indigenous Amerindians and the Afro-Ecuadorians" (para. 1). This information is in accordance with the 2010 nationwide census, conducted by the Ecuadorian Institute of Statistics and Census (INEC), in which the following information about the country's ethnic groups was found: Mestizo (mixed Amerindian and Spanish) 71.9\%, Montubio (mixed heritage of Spanish, Indigenous, and Afro-Ecuadorian culture) 7.4\%, Afro-Ecuadorians 7,2\%, Indigenous (Amerindian) 7.0\%, Spanish and Other 6.5\%. Such statistics lead us to picture how a classroom may look like in some parts of Ecuador.

On the basis of our teaching experience, we have not had yet a diverse classroom in terms of varied ethnic groups and nationalities. Thus, we have not experienced a classroom consisting of students from Qechua-speaking and varied cultural backgrounds, and countries, especially from countries, such as Colombia, Peru, and Cuba. However, there were few students from different Ecuadorian regions, namely Pacific Coast Region, Amazon Region and Highlands Region, in our classrooms. On the other hand, we are well aware that Ecuadorian teachers sometimes have in their classrooms students from these countries because they come along with their families to our country as a result of migration. In addition, when we taught in private schools, our classrooms were a little more diverse. We had a few students from other countries, including England, Ireland, India, and China. We were not the English instructor of these international students for a long time, but a couple of months only. We also experienced a classroom where there was an autistic student and other students who were below grade level. As stated above, at the public schools where we have taught our classrooms were not culturally and linguistically diverse. Additionally, at public schools, we have not carried out any kind of procedure for identifying whether or not students had learning disabilities. We could notice that few students had dyslexia at the moment they were required to work on a certain task that require the use of their native language, that is, Spanish (L1).

For the purpose of this paper, we will focus on our last teaching situation before we pursued graduate studies. We taught six high school senior classes at a school located in the district 1 in the Azuay Province. We taught English as foreign language (EFL), not any content-area subject, for over thirty class hours per week. All the students were male and their ages ranged from 16 to 18 years old. Most of the students were from the city area, while some students were from the countryside. About $80 \%$ of the students were from the city and $20 \%$ from places outside it (known as parroquias rurales). The main economic status was middle class; there were very few students who were either poor or and upper middle class. Their parents' highest level of education achieved was high school. Additionally, some students showed high levels of misconduct. Some students were also engaged in drinking and drug habits. Sometimes, students stuck around after classes and fought at a square near school.

At high school, our students pursued three different vocational specializations, including electrical work, automobile mechanic, and industrial mechanics. We learned that most of them enjoyed these specializations, and that was why they chose to study at a vocational school. This vocational school was popular because of soccer and because its graduates were able to work effectively in their specialized fields in local businesses of our home city. In fact, the school has won many soccer championships in the city's school soccer league, and some students have become professional players. In addition to soccer, our students enjoyed playing Ecuavolley (a variation of volleyball where three people play on each side) at every free moment. We enjoyed playing that with them as well. They even kind of instructed us how to play well; they were much better than us. Students could play sports at the school itself because there were some sports courts, or they could go to a nearby, big park to do so.

Most of our students did not do well in English class. They were at the last grade of high school, and usually these grade-level students are supposed to have a good understanding of the basics of the English language as well as to use the target language for basic written and oral communication effectively. Through the administration of a diagnostic test we learned that most of students were below grade level. And through daily teacher-student interactions we also learned that $80 \%$ of the students did not have a good command of the English major skills (reading, writing, speaking, and listening). Between $10 \%$ and $20 \%$ of the students were able to complete the learning activities successfully. Probably, most of the students were struggling because of previous not-so-good English learning experiences, as well as unidentified learning disabilities and needs along the course of our instruction, their time spent and greater commitment towards classes of their specialization and sports, and their lack of interest in learning the English language. 
Finally, we want to wrap up this section of the article by pointing out that some of the struggling students and average students did well on their classes towards their school specialization. For instance, they enjoyed being able to work on a car engine and help doing electrical work activities around the school. In short, they loved using their hands to fix and create things. On the other hand, honestly we do not think we did a good job in identifying our students' needs or working on meeting the needs that we were actually able to identify during the course of instruction. In order to meet some of the needs of our students, our instruction should have been based more on an approach consisting of hands-on learning, kinesthetic intelligence, and above all, differentiated instruction lessons.

\section{Where Theory Meets Practice: DI in the EFL Ecuadorian Classroom}

\section{A. EFL Standard - English Education at the High School Level}

Summarize and give their opinion about a short interview, documentary, book, film, discussion, etc., and answer further questions of detail. This standard entails three major skills-summarizing, giving opinions, and providing detailed information about written and spoken sources of information. This requires students to engage carefully in reading and listening activities in order to extract key information needed for summarizing, giving opinions about, and answering information questions about passage content. This standard is written for high school senior grade level. On the basis of our experience, we have learned that high school seniors do not feel confident to use the target language for communication, both in oral and written manner. They struggle conveying their opinions, feelings and thoughts in their L2. They usually mention that it is much easier for them to understand spoken language during conversations rather than producing the language needed to interact with others around them outside the classroom. Usually, there are only few students who are able to use the English language for communicative purposes in the classroom, but they are not proficient speakers. They are able to function in basic communicative situations that involve exchanging their own and their families' information. Therefore, we strongly believe that using differentiated instruction (DI) will be key in helping language learners accomplish the aforementioned standard by meeting the varied English proficiency levels present in the classroom.

We will first employ different procedures to make informed decisions during instructional practice at the moment of differentiating the content, process, product and learning environment at our classroom setting. To incorporate a differentiated instruction model in the classroom, an inventory or learning styles questionnaire will be administered early in the year so that we can use that information for grouping students into groups and differentiating the content, process, and product (Levy, 2008). We will also use formative assessment with the aim of identifying students' proficiency level of the four major English language skills through observations, informal interviews, checking students' works. The criteria for grouping students into groups for classwork will consist of the interests, readiness levels, and learning profiles we will find out during the course of instruction. By making modifications, we will support and improve student learning because learners will grasp key aspect of instruction in the most effective way (Pham, 2012).

In short, in this paper EFL Ecuadorian teachers can find key information and the necessary tools to better help their students accomplish standards established for the enhancement of English education by implementing DI in the English classroom setting. The first part of the chosen standard (for illustrative purposes) is concerned with summarizing different sources of information, such as a short interview, documentary, book, film, discussion, etc. The second and third part of the standard, giving opinions and providing detailed information when asked respectively, may be addressed in subsequent lessons.

\section{B. Differentiating Instruction through Content}

The input provided needs to be challenging but manageable for all learners. If the input does not have these characteristics, learners will fall behind in the learning process and feel unmotivated (Bigge and Shemis, 2004). With this key notion in mind, we will differentiate the input by giving special emphasis on the most relevant and essential components of the intended standard for learners to accomplish (Theisen, 2002). Providing learners choices will be key in our efforts to meet their needs. In addition, if our students need more time and further practice to obtain the knowledge and skills needed to accomplish the standard, our teaching will be remained flexible and intended to suit their needs.

A learning-center approach will be employed to introduce students diverse learning materials. This approach consists of a classroom containing a collection of materials or activities aimed at teaching, reinforcing, or extending a particular concept or skill (Theisen, 2002). We will have students choose from various learning centers consisting of a movie center, historical event center, biography center, travelling center, entertainment center, and interview center. In each center students can both read and listen to a passage featuring a story. One of the learning center activities involves having students make notes of the main ideas and essential details from either the reading passage or the listening passage. After that, students will be assigned to groups of three to share their key notes. Again students will be required to choose another learning center that interest them. They will need to choose a new learning center that provides them with a different input experience; this means if they first choose a learning center that featured a reading passage, they will now need to switch to a learning center that has a listening passage. In their new learning center, students will also 
need to make notes about the essential information of the passage. They will be assigned new groups where they will share their notes again. After the students experience two different learning centers, we will ask them to choose the learning center that they feel more comfortable with. Finally, we will have students choose one more learning center; they will be encouraged to choose the new learning center based on their interest and preferred learning styles. In others words, each student's final learning center will be the center that was reported to be the one in which she or he feels more comfortable with. To wrap up this learning experience, the ticket-out strategy will be utilized. Students will need to write between two and four sentences that summarize the content of the last passage they work on, which requires them listen for the gist, listen for specific details, share notes, discuss the key points of the passage content, and write a mini-summary.

In the aforementioned learning centers, students were able to encounter multiple opportunities to read and listen to input, practice skills needed for writing a summary, and engage in cooperative learning. This is quite important because learning centers are intended "to provide differentiated learning experiences for [all] students" (Watts et al., 2012, p. 307).

\section{Differentiating Instruction through Process}

As stated by Pham (2012), modifying the process in a differentiated classroom involves using varied activities, techniques, and teaching strategies and organizing instruction from easy to difficult levels of understanding. These help students make sense of meaning and engage in the instructional process. With this in mind, we are interested in expanding the learning experiences students had in the learning centers by using pair work. The criteria we will use to pair up students will be based on the different learning styles we found in the inventory administered. Moreover, another criterion will be pairing up students according to their preferred learning center (grouping by learners' interest). we will hand each pair a set of slips of paper with key sentences outlining the passage content from the pair's preferred learning center. After that, the pairs will need to put the slips of paper in order to complete a summary of the passage they either listened or read, and wrote notes about when they participated in the learning centers. Each pair will then discuss if their key notes are in the summary they arranged from the previous activity. In an oral manner, each pair will report their completed summaries to the whole class.

The activities we had students do above help us conduct formative assessment of our students' learning and needs. In this way we will have a better idea where our students are with regard to skills needed for summarizing as well as their reading and speaking levels. Thus, we will adjust our teaching to reflect our students' identified needs. At this point of instruction, we will help students build on their prior knowledge, as well as we will help them improve their language skills and meet their needs with the aim of advancing their learning towards summarizing (Levy, 2008). Modifications to the process will involve adding greater complexity to the learning activities, engaging students in creative thinking, and increasing the variety of ways students experience learning (Heacox, 2012). To differentiate the process, a choice menu could be designed (as the one below), that is, a differentiated strategy that "provides options for learners to practice skills, try new products, and work with a variety of resources as they learn" (Theisen, 2002, p. 4).

\begin{tabular}{|c|c|c|}
\hline $\begin{array}{l}\text { 1 Practice: Identifying the main ideas } \\
\text { (skimming) } \\
\text { - Go to this Y or X website. Read carefully } \\
\text { the tips and do the exercises. }\end{array}$ & $\begin{array}{l}2 \text { Practice: Extracting the essentials details } \\
\text { (scanning) } \\
\text { - Read the tips, and then choose an interview } \\
\text { and listen to it. Write the essential details of } \\
\text { it in the table provided. }\end{array}$ & $\begin{array}{l}\text { 3 Practice: Working on sentence connectors } \\
\text { - Complete exercises } 3 \text { and } 4 \text { in the workbook. }\end{array}$ \\
\hline $\begin{array}{l}4 \text { Practice: Synthetizing information } \\
\text { - Do the exercises on synthetizing } \\
\text { information on pg. } 58 .\end{array}$ & $\begin{array}{l}5 \text { Practice: Paraphrasing ideas in your own } \\
\text { words } \\
\text { - Work on a worksheet-exercises } 9,10 \text {, and } \\
11 .\end{array}$ & $\begin{array}{l}6 \text { Practice: Note taking } \\
\text { - Watch this Y or X video and practice this skill. }\end{array}$ \\
\hline \multicolumn{3}{|c|}{$\begin{array}{l}\text { Choose } 3 \text { boxes. Choose skill activities that will help you improve summarizing. } \\
\text { Student's name: } \ldots \ldots \ldots \ldots \ldots \ldots \ldots \ldots \ldots \ldots \text { Class: } \ldots \ldots \ldots \ldots \ldots \ldots \ldots \\
\text { Signature: } \ldots \ldots \ldots \ldots \ldots \ldots \ldots \ldots \ldots \ldots \ldots \ldots \text { Date: } \ldots \ldots \ldots \ldots \ldots \ldots \ldots\end{array}$} \\
\hline
\end{tabular}

This menu contains common problems our students had when working on a summary before in class. In order for students to be better prepared to write and present summaries, they will need to make at least three choices that provide them with practice aimed at improving their weak areas. In this activity, students have a sense of autonomy to select what they need to in order to be able to write a summary effectively and accomplish partially the intended standard discussed previously. They also become responsible for their own learning and enjoy a sense of freedom as well.

\section{Differentiating Instruction through Product}

Students will be allowed to perform different forms of assignments. The assignments will reflect what students have learned and how they can apply the new knowledge and skills gained to practical situations (Pham, 2012). In order to differentiate the product, students will be encouraged to produce a piece of work that summarizes the content of a written or spoken source of information in multiple ways. Their final products will match their learning strengths, reflect student learning styles and abilities, and encourage learners to take on challenging work. Students' products will involve variety, creativity, and learning in use (Heacox, 2012; Levy, 2008; Thiesen, 2002). 
Students can choose to summarize a listening or written text. Either way, they will need to employ the strategies and skills they have practiced along the lesson. Bloom's Taxonomy and Gardner's Multiple Intelligences Theory will be applied to the differentiation of products. In this respect students will come up with a summary in one of the following ways: acting out a role-play, creating a song, making a collage, preparing a speech, preparing a multimedia presentation, and creating a story. In any product students choose to work on, they will need to provide the main ideas and essential details from the source of information they have chosen to summarize. For instance, if a student chooses to elaborate a collage about a documentary, s/he will present a work that includes pictures or drawings representing the main points and critical details. The student will be encouraged to include key words that help him/her share the summary verbally. Therefore, students will have visual aids and key words as support for presenting the summary to the whole class. Another option is to act out a role-play, where a small group of students prepare a script based on their summary of a passage. Then they will present a role play convening the main ideas and important details from their summarized source of information. Preparing a speech is another way to differentiate the product; here students present their summaries in a form of a speech. They will need to keep eye contact and use clearly audible voice when presenting summaries in a speech version. A scoring rubric for grading students' final product should be elaborated. We need to make sure that students clearly understand our expectations. In Heacox' words (2012) the criteria for a rubric need to be clear and concise, yet specific, in students' language, a reflection of high expectations, written as positive statements, and encouraging effort and not setting limits.

\section{E. Differentiating Instruction by Adjusting the Learning Environment}

Despite the fact that at public schools we, language teachers, do not have our own classrooms, we should strive for making a learning physical environment appealing and helpful for our students, so that they can engage in and get the most out of each lesson. Therefore, with the aim of preparing a classroom setting for differentiated instruction, modifications on seating arrangements are needed to better allow students engage in diverse learning opportunities, including individual work, collaboration, pair work, groupwork, and whole-class instruction. As a matter of fact, from a differentiated instruction point of view, not all students learn in the same way so that different modes of teaching are needed to help students make sense of the new leaning (Thiesen, 2002; Pham, 2012). With this in mind, Gibson (2010) suggested that students need to be assigned to small groups for guided practice and direct instruction (if this is needed). Daily class sessions should include short minute time periods for whole class and small group instruction. Whole class activities should be used for introduction, overview, and quick review as well. Independent work should be completed when students work alone at their desks.

In a differentiated classroom it is pivotal to arrange the teaching-learning space and include some student work areas. For instance, to carry out more effectively the learning activities aimed at helping students produce summaries, one or two areas in the classroom will be needed for small group and teacher-led instruction (also known as the teaching table). According to Gibson (2010), teaching tables entail a performance expectation to the student. When students take part of teaching tables, they experience new and more challenging content along with teacher direct participation and constructive feedback provided. "Teacher-led, explicit, student-focused instruction, differentiated and specific to needs, occurs at the teaching table" (Gibson, 2010, p. 2). Furthermore, areas will be needed for workstations where students gather and work collaboratively. Before my instruction begins, we should create a few small group/partner work areas in the classroom. To do that, we can push desks together to form larger table spaces or have sometimes students work on the floor as well. If students need hard surfaces for writing tasks, they should be provided with clipboards. When students need to work on activities independently, such as reading, listening, and making notes, they will use the designated space to complete their independent work.

Within a differentiated classroom environment, we, teachers, need to allow students to begin their homework assignments in class. This will provide students with accessible support while they are still in the classroom. In this way, students will be more likely to complete assignments at home with ease and confidence. The designed assignments will be intended to give students further practice and reinforcement on the essential components of the content previously instructed and practiced over the course of my instruction (Gibson, 2010). In addition to these, further practices can be implemented into the classroom to help us run daily teaching practice smoothly: we can discuss and practice procedures used to break the class into groups. We should discuss expected behavior for collaboration, participation, pair/group work, sharing ideas and listening carefully. We could also talk with our students about the learning activities designed to provide different, meaningful learning experiences for all students based on the fact that we all learn differently. The different learning activities are intended to help all the learners to accomplish the same goal or standard; for instance, being able to summarize a short interview, documentary, book, film, and discussion, which was highlighted above. We may make arrangements for appropriate group work through the use of workstations, where students can have access to supplies and resources so that they do not waste valuable time moving around to get what they need to complete a task. We can use boxes where students can put their works, in case they need to complete them next class. Finally, we should use bulletin boards to post directions and students' work samples (Heacox, 2012).

\section{CONCLUSIONS}


After we have explored differentiated instruction in an enriching and in-depth manner, we reflected upon instructional practice along the completion of this paper and have become aware that one size does not fit all. Furthermore, we have realized that we have utilized differentiated instruction in the classroom to a certain degree, but not in a systematic manner. We have not made modifications on all the major areas that need to be differentiated $a s a$ way to response to student needs as effectively as possible, which is in line with Heacox' work (2012). We become aware that a differentiated classroom does not only involve giving struggling students more time to work on an assignment and using different types of assessments but, most importantly, experiencing a true differentiated classroom involves planning in mind with our students' different backgrounds, needs, interests, range of ability levels, and variety of learning profiles. Because in a true, actual differentiated instruction model students are given opportunities to reach their potential and succeed by putting them at the center of teaching and learning, fostering equity and excellence, and acknowledging each student's uniqueness.

Upon the completion of this paper, we feel equipped with the knowledge and skills needed to make future classroom instruction more responsive to our students' needs, ability levels, and learning styles, as well as recognize student voice as central in the teaching-learning process in the language learning classroom. As a systematic approach to differentiation of the content, process, product, and learning environment is incorporated into classroom practice, lessons will be more effective and consistent, which in turn facilitate student language learning. As a matter of fact, language classroom instruction needs to consist of tiered lessons including homework assignments, learning activities, readings, materials, and assessments that better reflect students' needs, readiness levels, and leaning profiles. In doing so, we will be more likely to meet our students where they are in the learning continuum and move them forward toward meaningful and successful educational experiences.

\section{REFERENCES}

[1] Allington, R. (2003). The schools we have, the schools we need. Retrieved June 5, 2017 from 1rtinvite.html.

[2] Bigge, M., \& Shermis, S. (2004). Learning theories for teachers (6th ed.). Boston, MA: Pearson.

[3] Gibson, V. (2010). Differentiating Instruction: Teaching Differently to Improve Student Outcomes. Retrieved July 20,2017 from http://www.compasslearning.com/files/docs/1252WP-DIFINST-1110-WEB.pdf.

[4] Heacox, D. (2012). Differentiating instruction in the regular classroom . Minneapolis: Free Spirit Publishing Inc.

[5] INEC. INEC Resultados. Retrieved June 13, 2014, from INEC Web site: http://www.ecuadorencifras.gob.ec/resultados/.

[6] Jackson, S. (2007). Country studies series: Ecuador. Retrieved June 14, 2014 from Coexistence International at Brandeis University: http://www.brandeis.com/globalbrandeis/documents/Ecuador_FINAL.pdf.

[7] Lawrence-Brown, D. (2004). Differentiated instruction: Inclusive strategies for standards-based learning that benefit the whole class. American Secondary Education, 32(3), 34-62.

[8] Levy, H. (2008). Meeting the needs of all students through differentiated instruction: Helping every child reach and exceed standards. $\quad$ Retrieved July 20, 2017 from http://www.wou.edu/ tbolsta/web/texbook/24_Meeting_the_Needs.pdf.

[9] Logan, B. (2011). Examining differentiated instruction: Teachers respond. Research in Higher Education Journal, 13(3), 1-14.

[10] Pham, H. L. (2012). Differentiated instruction and the need to integrate teaching and practice. Journal of College Teaching \& Learning, 9(1), 13-20.

[11] Reis, S., McCoach, B., Little, C., Muller, L., \& Kaniskan, B. (2011). The effects of differentiated instruction and enrichment pedagogy on reading achievement in five elementary schools. American Educational Research Journal, 48(2), $462-501$.

[12] Rock, M. L., Gregg, M., Ellis, E., \& Gable, R. A. (2008). REACH: A framework for differentiating classroom instruction. Preventing School Failure, 52(2), 31-47.

[13] Sapon-Shevin, M. (2000/2001). Schools fit for all. Educational Leadership, 58(4), 34-39.

[14] Scott, B. (2012). The effectiveness of differentiated instruction in the elementary mathematics classroom. Retrieved June 7 , 2014 from The effectiveness of differentiated instruction: http://cardinalscholar.bsu.edu/bitstream/123456789/195872/1/ScottB_2012-2_BODY.pdf.

[15] Smit, R., \& Humpert, W. (2012). Differentiated instruction in small schools. Teaching and Teacher Education, 28(8), 11521162.

[16] Subban, P. (2006). Differentiated instruction: a research basis. International Educational Journal, 7(7), 935-947.

[17] Theisen, T. (2002). Differentiated instruction in the foreign language classroom: Meeting the diverse needs of all learners. The Communiqué, 6, 1-8.

[18] Tomlinson, C., Brighton, C., Hertberg, H., Callahan, C., Moon, T., Brimijoin, K., Reynolds, T. (2003). Differentiating instruction in response to student readiness, interest, and learning profile in academically diverse classrooms: A review of the literature. Journal for the Education of the Gifted, 27(2) 119-145.

Diego P. Ortega is an instructor and researcher at Universidad Nacional de Educación in Azogues, Ecuador. He teaches undergraduate courses dealing with learning theories, curriculum development, English as a foreign language and educational research. He has been an instructor at the university level for over seven years. He earned his bachelor's degree in Educational Sciences, concentration in English Language and Literature, at Universidad de Cuenca, Ecuador. He also holds a master's degree in Curriculum and Instruction with emphasis in TESL from Kansas State University. In addition to it, he pursued postgraduate studies in Linguistics and Foreign Language Teaching at Universidad Central del Ecuador. His past and current research interests revolve 
around the English curriculum within the Ecuadorian context, educational and second language research, contemporary/communicative language teaching methodologies, language teacher education and initial teaching skills.

Johanna M. Cabrera currently works as an instructor at Universidad Nacional de Educación in Azogues, Ecuador in the Basic General Education major. She has also worked in the Ministerio de Inclusión Económica y Social (MIES), positioned as Pedagogical Coordinator. In addition, she has been part of the Ministerio de Educación (MINEDUC) by working in the teaching areas of regular and special education for several years. She holds an undergraduate degree in Early Stimulation in Health obtained at the University of Cuenca, as well as a master's degree in Intervention and Initial Education from University of Azuay in Ecuador. Her topics of interest in research are related to special education, detection of development retardation, educational insertion in the regular teaching units, among others.

Jhonny V. Benalcázar has been an English teacher for eight years in public and private educational institutions in the city of Cuenca, Ecuador. He also finds ways to enhance his professional teaching practices and student language learning, so that he is committed to strive for excellence in the area of English education at the public sector. He earned a bachelor's degree in ELT at Universidad of Cuenca, and he is currently pursuing graduate studies on Linguistics Applied to Teaching English as a Foreign Language at the same institution of higher education. His research interests deal with the application of the CLIL approach in the classroom setting of secondary education, the development of L2 students' productive language skills, and the Ecuadorian EFL curriculum. Furthermore, he is interested in researching about the use of technology in English language teaching and learning in Ecuadorian classrooms. 